\title{
Occupational Influence on Women's Attitude Towards Oral Health in the Enugu State, Nigeria
}

\author{
Rita Ngozi Ani and U. C. Nnabueze \\ Department of Health and Physical Education \\ Enugu State University of Science and Technology, \\ Enugu, Nigeria \\ E-MAIL: nna bueze@yahoo.com \\ DOI: http://dx.doi.org/10.4314/gjds.vgi2.7
}

\begin{abstract}
This paper investigated the influence of occupation on women's attitude towards oral health among women attending Primary Health Care (PHC) Centres in the Nkanu West Local Government Area of Enugu State of Nigeria. Three hundred and forty seven (347) women were selected from 2,608 women who formed the population using simple random sampling with nonreplacement balloting technique. The instrument for data collection was the self-constructed questionnaire. The questionnaire had 14 items based on four point scale and had a Spearman Brown's reliability co-efficient of 0.79. Data was analyzed using criterion mean while ANOVA was employed in testing the null hypothesis for the study at a 0.05 level of significance. The findings of the study revealed that the respondents agreed that occupation influences the attitude of women towards oral health. Also, it was identified that the influence was negative. Based on the findings, it was recommended that women should be enlightened more on the influence of occupation on their oral health. Furthermore, women should be sensitized on the need to prevent oral health problems.
\end{abstract}

KEY WORDS: Oral Health, Human Wellbeing, Occupational Health, Women's Attitude, Primary Health Care

\section{Introduction}

Oral health is fundamental to general health and wellbeing. It has significant impacts on the quality of life. Through oral health, the overall health and wellbeing of a person is enhanced. According to Collins, Walsh and Figures (1999) and American Surgeon General Report (2000), oral health means more than healthy teeth and the absence of diseases. Rather, it involves the ability of individuals to carry out essential functions such as eating and speaking as well as contributing fully to the society. Furthermore, to the World Health Organization (WHO, 2003) oral health enables an individual to speak, eat and socialize 
without active disease, discomfort or embarrassment. Hence, poor oral health can affect general health conditions.

Encarta Premium (2000) has pointed out that humans use their teeth to tear, grind and chew food as a first step of digestion. This enabled enzymes and lubricants to be released into the mouth for the further break down of food. The mouth (oral cavity) also plays a role in human speech - the teeth, lips and tongue are used to form words by controlling air flow through the mouth. In addition, the teeth provide structural support to the muscles in the face and form the human smile. However, most food and water borne diseases can be prevented through paying meticulous attention to good oral health practices and formation of positive attitudes toward oral health (WHO, 2003) but be as it may the above definitions and explanations of oral health appears to be elusive among women in the study area.

The consequences of diseases in the mouth include pain and infection as well as poor concentration at work, reduced ability to chew food, poor appearance and lose of teeth. According to American Dental Association (ADA) (2003), women with poor oral health, face the above mentioned health problems in addition to giving birth to under weight babies. Furthermore, women's failure to maintain an appreciable level of oral health puts their babies and households at risk of contracting germs from them (Aderinokun, 2000).

Women's level of health is important for the whole family because of the responsibilities they perform which include child bearing, care giving, earning income, domestic chores, career development and educational goals, to mention but a few. Despite all these, women seem to suffer from many preventable oral diseases and injuries necessitated, by their nature as women and the type of work they do. Consequently, it has been observed by researchers (Arkutu, 1995, ADA, 2003 and Azubike, 2005) that women are often too busy to keep their oral cavity clean and to give themselves good health care in general. Furthermore, women's lack of autonomy and mobility which is shown by their need to receive permission from their bosses and partners to seek for medical care however contributes to women's attitudes to their general health and their oral health in particular. Also, women working and living on farms as well as those working outside of their own agricultural land and home have to receive permission from bosses or managers to seek for medical care. Such women may be discouraged from accessing health services including oral health service because they may fear straying from their role as care takers by leaving their children, husband, business and homes unattended in other to commit an amount of time to seeking health care. Hence, the impact of poor oral conditions on women's wellbeing is a private experience, endured from day to day, yet this silent suffering creates substantial excruciating pains on them. The extent to which women grapple with the effect of poor oral health may be linked to the occupational influence on their attitude towards oral health.

Attitude is one's feeling towards an object, person or thing. Osarenren (1996) defined attitudes as the mental and neutral state of readiness organized through experience, 
exerting a directive or dynamic influence upon the individual's responses to all objects and situations which it is related. Adeleke (1994) observed further that women have developed overtime the attitudes of no pain, no problem. Hence, Khosravi, Farrokhi, Ahmadi and Servati (2004) noted that with respect to the attitudes of women towards oral health, it is an unfavorable and unwelcome situation, which needs urgent attention. This attitude according to Slande and Sander (2004) may be attributed to their feeling that the impact of poor oral conditions on well-being is a private experience endured from day to day, yet this silent suffering creates substantial excruciating pains on them. In the context of this study, therefore, attitude is viewed as a feeling, thinking, or emotions that predispose women to respond either positively or negatively towards their oral health care, towards people with poor oral health and towards poor oral health. Perhaps ascertaining the influence of occupation on women's attitude towards oral health may be a way forward to attending to women's poor oral health.

The term occupation takes on various meaning depending on the contexts of its use. As a descriptive characteristic of individuals, it generally refers to one's employment. As an epidemiological and demographic variable, it most typically serves as a surrogate measure of socio-economic status. As a family variable, occupation of the main earner often stands as an indication of family's socio-economic status. According to Hansen, Bjertness, Gronnesby and Eriksen (1995) occupation masks other factors that affect oral health. Arowojolu (2001), for instance, noted that occupation of parents may be a direct measure of educational and socio-economic status of the family. In line with this, occupation therefore was a necessary factor to be ascertained in this study. The classification of occupation, according to Famuyinwa and Olorunshola (1998), was adopted in determining the occupation of the women. Despite the above assertions, the influence of women's occupation on their oral health, has not been empirically ascertained in the study area, hence the need for the study.

This study was anchored on the Theory of Reasoned Action (TRA), which emphasizes that attitude and subjective norms determine or are the best predictors of one's stated behavioural intention (Ajezen, 1991). According to this theory, the intention to carry out a given health behaviour is often a function of privately held attitudes towards that particular behaviour and socially-determined subjective norms that represent a person's belief that others think she or he should behave in a certain way. This theory links health attitudes directly to behaviour. TRA stresses that one's attitudes toward a particular behaviour are influenced by belief outcome of the behaviour and one's evaluation of the potential outcome.

This theory by extension can be used to analyze the influence of occupation on the attitudes of Nkanu women towards oral health. It then follows that if it is found that occupation of the women has a negative or positive influence on their attitude towards oral health, then they will be more likely to adjust their work where applicable in other to embrace positive attitudes towards oral health. On the basis of this, the problem of the study was to ascertain the influence of occupation on the women's attitudes towards 
health, among women attending the Primary Health Care (PHC) centers in Nkanu West Local Government Area, Enugu State. Specifically, the study aimed to determine the influence of occupation on women's attitude towards (i) their oral health care (ii) people with poor oral health (iii) oral health problems. To further aid the study, three corresponding research questions and one null hypothesis were raised as follows: how does occupation influence women's attitude towards (1) their oral health care? (2) people with poor oral health? (3) oral health problems?

\section{Methods}

The study was a survey research, designed to ascertain the influence of occupation on the women's attitude towards oral health among women attending the PHCs for antenatal and immunization clinics in Nkanu West Local Government Area, Enugu State. The population for the study comprised all the 2,608 women attending the antenatal and immunization clinics at the nine PHC centers located in the nine towns that make up the local government area. In determining the sample size, the Yaro-Yamane formular was adopted and the sample size of 347 was drawn. According to Uzoagulu (1998), this formular is appropriate when the population of the study is finite. Using simple random sampling with non-replacement balloting technique, 347 women were drawn to form the sample for the study.

The research instrument used was a 14 item self-developed and structural questionnaire, designed in a four point rating scale: strongly agree (4 points), agree (3 points), disagree ( 2 points) and strongly disagree ( 1 point). The face validity of the research instrument was established by giving the instrument and the research questions of the study to three experts in oral health. Their criticisms, advice and suggestions were used in modifying the instrument that was used for data collection. The reliability of the instrument was ascertained through test re-test of the instrument on women who are not part of the study. The scores obtained from the two tests were correlated using Spearman Brown correction formula and it yielded a reliability coefficient of .79 , which shows a high relationship. The instrument was, therefore, considered reliable for use in the study. A total of 347 copies of the questionnaire were distributed and returned by the researcher with the aid of nurses in the PHC centers. Three hundred and forty three (343) copies of the questionnaire were properly filled and therefore were used for the study. This gave $89.8 \%$ return rate. This was adjudged high enough for the study. The descriptive statistics of mean and standard deviation were used to analyze the data. A criterion mean of 2.5 was established. Mean scores of 2.5 and above were regarded as agree while scores below 2.5 were regarded as disagree. By this decision, whenever there is mean of means of 2.5 and above, it is regarded as agree while mean of means below 2.5 is regarded as disagree. Furthermore, ANOVA was employed in testing the only null hypothesis for the study at the 0.05 level of significance. 


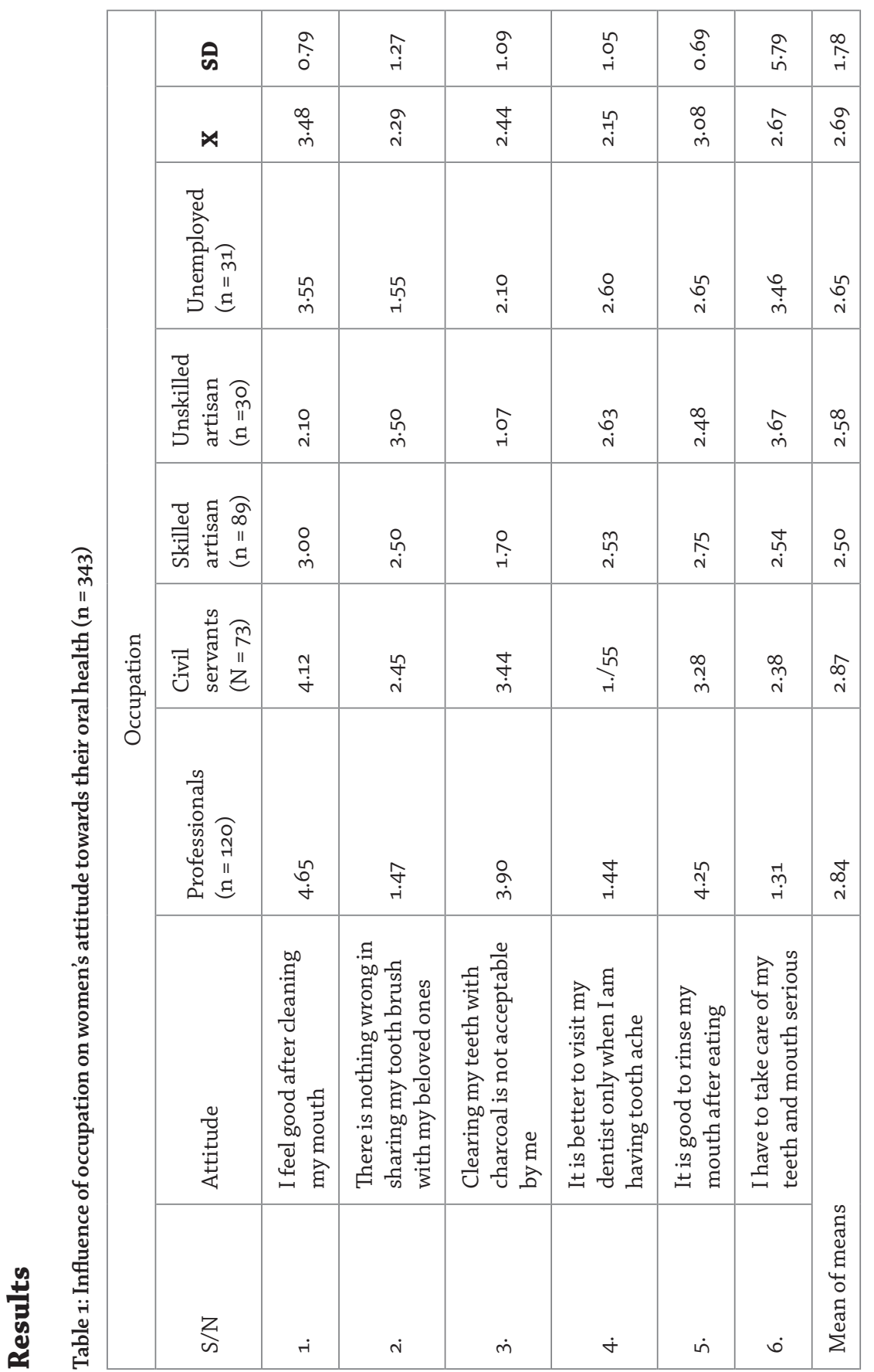

กิ 

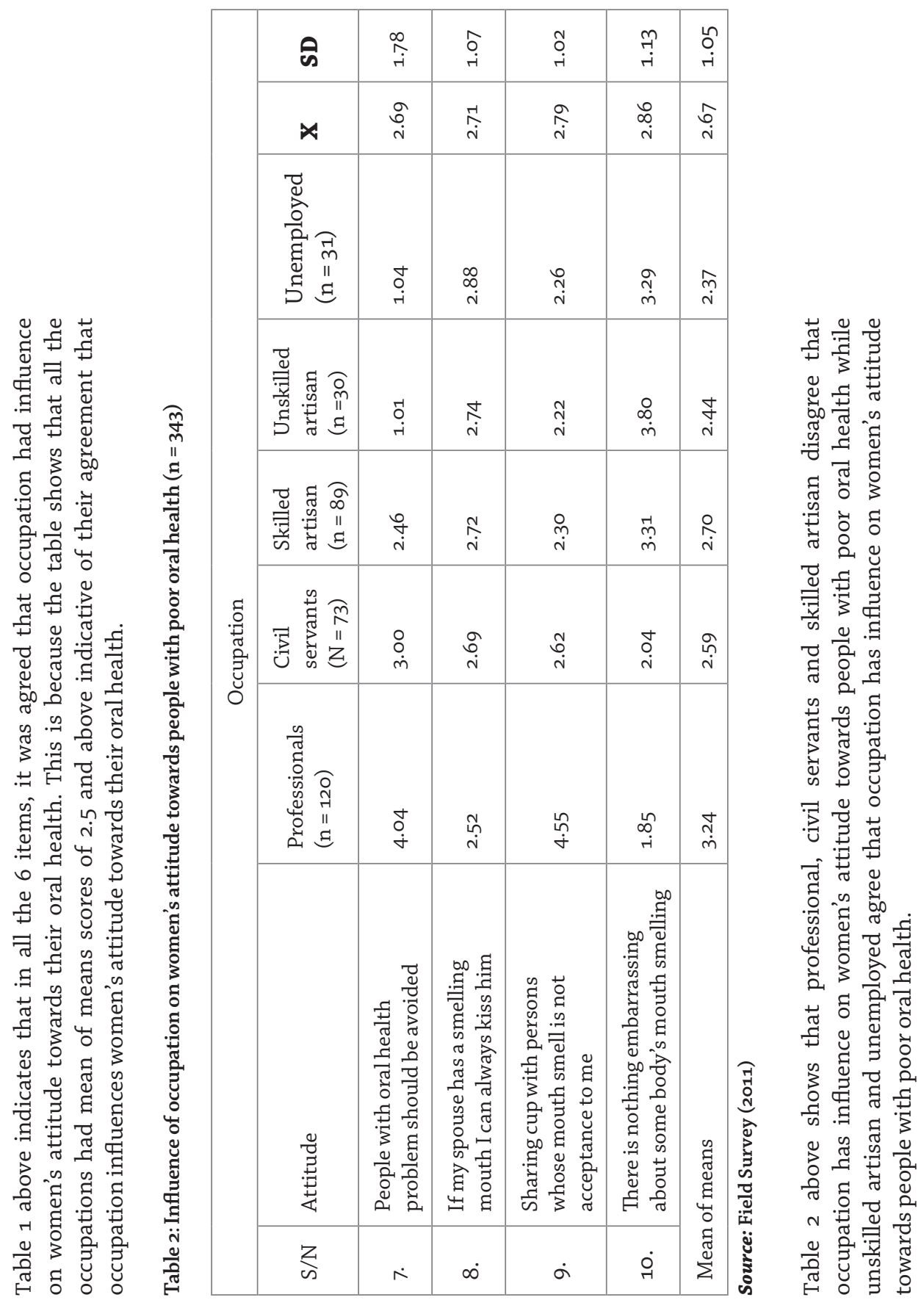

130 GJDS, Vol. 9, No. 2, October, 2012 


\begin{tabular}{|c|c|c|c|c|c|c|}
\hline \multirow{9}{*}{ 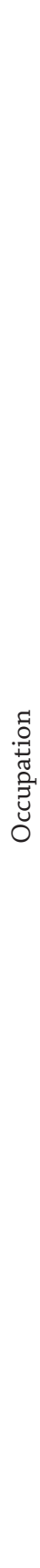 } & ผ & $\begin{array}{l}\infty \\
\stackrel{+}{+} \\
\text { - }\end{array}$ & o. & gे & o. & $\begin{array}{l}\infty \\
\alpha \\
0 \\
\dot{0}\end{array}$ \\
\hline & $x$ & $\begin{array}{l}\text { Ọ } \\
\text { i }\end{array}$ & $\begin{array}{l}\Re \\
\stackrel{i}{i}\end{array}$ & 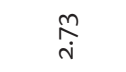 & $\begin{array}{l}0 \\
\underset{+}{0} \\
+\end{array}$ & $\begin{array}{l}\overrightarrow{7} \\
\stackrel{\text { i }}{1}\end{array}$ \\
\hline &  & $\begin{array}{l}\vec{H} \\
\text { ì }\end{array}$ & 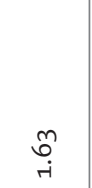 & 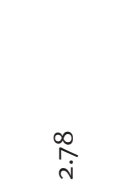 & $\underset{i}{\mathbb{H}}$ & $\begin{array}{l}\stackrel{n}{r} \\
\dot{i}\end{array}$ \\
\hline & 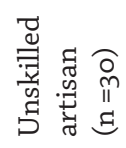 & $\begin{array}{l}\stackrel{L}{\hat{~}} \\
\text { i }\end{array}$ & $\hat{\tilde{r}}$ & 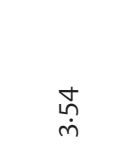 & 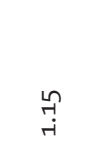 & $\stackrel{\text { n }}{\text { n }}$ \\
\hline & 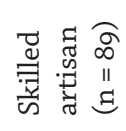 & 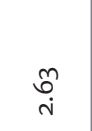 & $\underset{i}{+}$ & $\begin{array}{l}\infty \\
\infty \\
i \\
i\end{array}$ & $\begin{array}{l}\underset{H}{\rightarrow} \\
\rightarrow\end{array}$ & $\begin{array}{l}\hat{O} \\
\stackrel{i}{ }\end{array}$ \\
\hline & 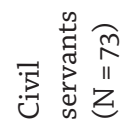 & $\begin{array}{l}\sigma \\
\text { ते }\end{array}$ & $\begin{array}{l}0 \\
\stackrel{\sim}{i} \\
\end{array}$ & 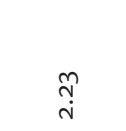 & $\underset{\dot{H}}{\widehat{~}}$ & $\begin{array}{l}\tilde{N} \\
\dot{i}\end{array}$ \\
\hline &  & $\begin{array}{l}\infty \\
\infty \\
0\end{array}$ & $\begin{array}{l}\hat{L} \\
\hat{m}\end{array}$ & 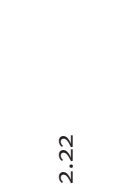 & $\begin{array}{l}\check{r} \\
\dot{m}\end{array}$ & $\begin{array}{l}\mathcal{Y} \\
\text { ì }\end{array}$ \\
\hline &  & 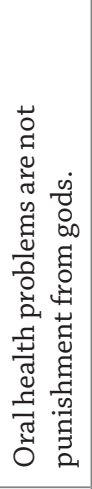 & 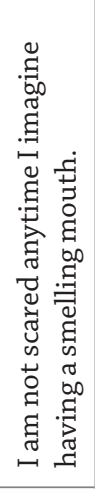 & 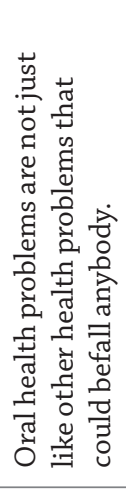 & 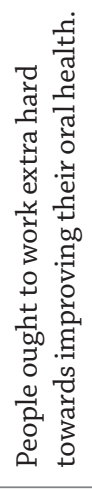 & 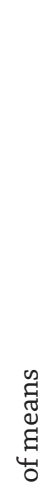 \\
\hline & $\frac{z}{\omega s}$ & $\overrightarrow{7}$ & 그 & $\dot{\sim}$ & ச் & $\sum^{\tilde{J}}$ \\
\hline
\end{tabular}

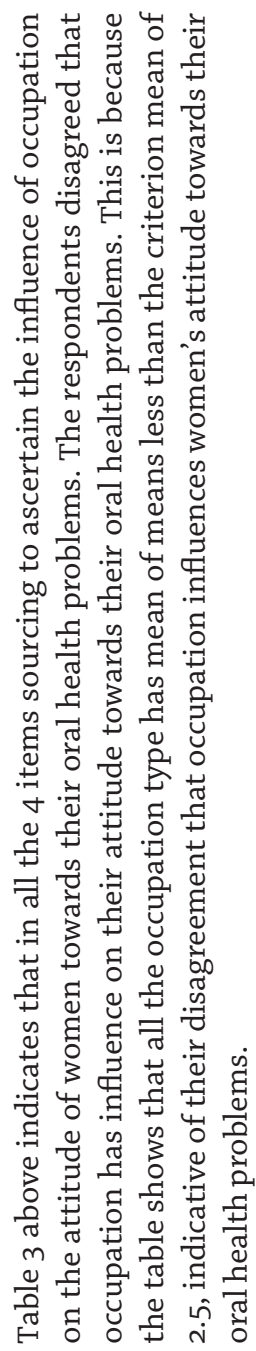


Table 4: Summary of ANOVA verifying the influence of occupation on women's attitude towards oral health $(\mathrm{n}=343)$

\begin{tabular}{|l|l|l|l|l|l|l|l|}
\hline $\begin{array}{l}\text { Sources of } \\
\text { variation }\end{array}$ & DF & $\begin{array}{l}\text { Sum of } \\
\text { Square }\end{array}$ & $\begin{array}{l}\text { Mean } \\
\text { Square }\end{array}$ & f-table & f.cal & Sing. & Dec. \\
\hline Between groups & 4 & 4.6341 & 1.1585 & .3872 & 1.0386 & .05 & Reject \\
\hline Within groups & 338 & 377.0277 & 1.1155 & & & & \\
\hline Total & 342 & 381.6618 & & & & & \\
\hline
\end{tabular}

Source: Field Survey (2011)

Table 4 above shows that from the F-ratio distribution, the critical value of $\mathrm{F}$ with 4 and 338 degrees of freedom at .05 level of significant is .3872 . Since the computed value of 1.0386 is greater than the critical value of .3872, the null hypothesis is therefore rejected. The women therefore differ in their attitude towards oral health based on their occupation.

\section{Discussions and Implications}

The study revealed that women agreed in their responses on the influence of occupations on women's oral health. This shows that the women's attitude toward oral health is dependent on their occupation. This influence may be negative or positive. The above finding is not surprising because it agreed with the findings of some previous authors such as Arowojolu (2001) who identified occupation as a major factor that influences people's attitude towards oral health. Al-shalam (2003) also agreed that significant differences were found when occupation was tested on the attitude of female parent towards oral health behaviour modification. This is consistent with Nwobodo (2007) who also established that women had negative attitudes towards oral health. Probably this negative attitude may be associated with the kind of work women do. Also it has been observed by Arkutu, (1995), ADA (2003) and Azubike (2005) that apparently due to the different responsibilities women perform in the family in particular and in the society at large, they are always too busy to consider their health care important.

Furthermore, women's lack of autonomy, which is shown by their need to take permission from their spouse before seeking medical help may have predisposed them to their negative attitude towards oral health because they fear straying from their role as care givers by leaving their children, husband, business and home unattended in other to commit an amount of time to seeking health care. Hence, they bear the impact of poor oral conditions on well-being privately from day to day. Yet, this silent suffering creates substantial excruciating pains on them. It has to be noted that the health of the mother could influence the health of the total number of members of the family because of the important part they play in the family. From the foregoing, the researcher concludes 
that the theory of reasoned action is a functional theory to base the attitude of women towards oral health. This is because according to this theory, the intention to carry out a given health behaviour is often a function of privately held attitudes towards a particular behaviour. According to the TRA, one's attitudes toward a particular thing are influenced by the subjective norms around them. Hence, the negative attitude of the women may be attributed to the privately held attitudes and norms that they might have developed about oral health based on the type of work in whey they engage.

The findings of the study have practical importance and far reaching implications on maternal and child health. Indications from the results showed that the kind of work women do influence their attitudes toward their general health and oral health in particular. This influence may be positive or negative. When the influence is negative as has been proved by some author's cited in this study, then, the implication is that the negative attitude of the women towards oral health will negatively influence the development of positive attitude of oral health of their family members especially the children. Since it has been observed that consequences of poor oral status of women has a far more consequence on the women, ranging from pains, infections, lower level of concentration at work, reduced ability to chew food, poor appearance and lose of teeth. Aderinokun (2000) specifically stated that women's failure to maintain an acceptable level of oral health puts their babies and households at the risk of contracting germs from them.

Consequently, the American Academy of Periodontogy (2003) observed that there is a marked elevation of sex hormones during pregnancy and as many as $75 \%$ of all women exhibit changes in their gum during pregnancy, which is known as pregnancy gingivitis. These tumors which bleed easily if manipulated, may progress into irreversible damage to the gums and ultimately the teeth. Perhaps this might inform the findings of Pace and DeAngelis (2001) who asserted that these oral infections during pregnancy can put the mother at risk of delivering a premature and low birth weight baby. Buttressing the above statement, the American Academic of Periodontogy (2001) revealed that pregnant women with gum diseases are more likely to have their babies born early and with low birth weight. People with gum diseases are more likely to develop heart diseases and untreated decayed teeth put a mother and her baby at high risk of infection. Therefore, it is extremely important that women in general and expectant mothers in particular have healthy mouths and see a dentist early in their pregnancy irrespective of their occupation, since it has been proven that the neglect of this aspect of the health of mother can pose serious health threats to the mother, the child, the family and the society at large.

\section{Conclusion and Recommendations}

The attitude of women toward oral health may be attributed to the type of occupations they do. The implication of this finding is that occupations may influence oral health attitudes positively or negatively. If it is negative, it may negatively influence the 
development of the attitudes of women and their family members especially children, negatively and vice versa. Following from this, there is need to make concretized and conscious efforts by the women themselves, and others around them to help improve the attitude of women towards oral health irrespective of the kind of occupation they may find themselves. Based on the findings of the study, the researchers recommended that:

- Women should be enlightened by the government through health workers on the influence of occupation to their oral health.

- Women should be sensitized by the educators on the need to prevent oral health problems than the cure, since prevention is better than cure, this they can do by developing positive attitude towards their oral health.

\section{References}

Adeleke, A. N. (1994). "Oral health education." African Health, 16(2), 1-2.

Aderinokun, G. (2000). An introduction to oral health care for community health workers. Ibadan: Kenbin Press Ltd.

Ajzen, I. (1991). "The theory of planned behaviour: Organizational behaviour and human decision processes," Organizational Behaviour 50, 179-211.

Al-shalan, T.A. (2003). "Factors affecting Saudi Parents' perception of their children's first dental visit." The journal of contemporary dental practice, 4(4) 54-66.

American Surgeon General Report (200o). The face of a child[online]. Available: DC.http://www.nidenih.gov/sgr/children.htm.

Arkutu, A.A. (1995). Healthy women, healthy mothers: An information guide. $2^{\text {nd }}$ Edition. New York Family Care International Inc.

Arowojolu, M.0. (2001). "Effect on social class of the prevalence and severity of periodontal diseases.” Nigerian Medical Practitioners, 39(1); 26-28.

Azubike, G.C. (2005). "Women and child nutrition: Implications for girl-child education." International Journal of Forum for African Women Educationalists, Nigeria (IJOFAWEN) Vol. (No. 1): 57-66

Collins, W.J.N.; Walsh, T.F., \& Figures, K.H. (1999). A handbook for dental hygienists. Oxford; Reed Educational and Professional Publishing Ltd.

Ecarta Premium (2000). Human Teeth. Microsoft Corporation, USA. 
Famuyiwa, D. and Olorunshola, D.A. (1998). "Some family factors in sickle cell anemia in Lagos, Nigeria.” Nigeria Medical Practitioner, 35(5/6), 70-73.

Hansen, B.F.; Bjertness, E.; Gronnesby, J.K.; and Eriksen, H.M. (1995). "Changes in periodontal treatment needs: A follow-up study of Oslo citizens from ages of 35 to 50 years." Journal of Periodontal Restruction 30, 410-417.

Khosravi, M., Farrokhi, R. Ahmadi, M.H. and Servati, z. (2004). "Attitude, knowledge and practice related to oral hygiene among urban Babolian Population between 2040 years old." Journal of Babol University of Medical Science. 2: 3-4.

Nwobodo, N.R. (2007). "Knowledge, attitudes \& practices of oral health among women attending the primary health care centers in Nkanu, West Local Government Area of Enugu State." M.Ed. Thesis. Department of Health and Physical Education, University of Nigeria Nsukka (unpublished).

Osarenren, N. (1996). Child development and personality. Lagos, NIgeira: Hiwits Ltd.

Pace, C. and DeAngelis, S. (2001). Oral health for women. American Dental Hygienists' Association.

Slande, G.D. and Sanders, A. (2004). The ICF and oral health. Adelaide, Australia: Australian Research Centre for Population Oral Health[online]. Available: gary. slade@adelaide.edu.au.

Uzoagulu, A.E. (1998). Practical guide to writing educational research. Enugu: Jacobs Books.

WHO (2003). Oral Health Promotion through Schools. WHO information series on school health. Document Eleven. WHO/NMH/NPH/ORH/SCHOOL/o3.3. Geneva. 